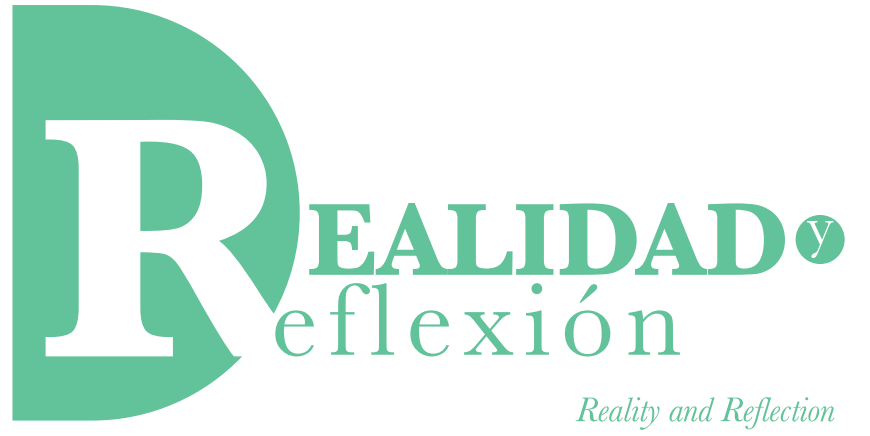

ISSN 1992-6510

e-ISSN 2520-9299

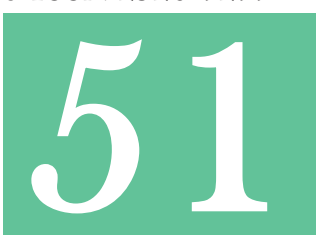

Año 20, N 51, San Salvador, El Salvador, Centroamérica. Revista Semestral Enero-Junio 2020

YEAR 20, $N^{\circ}$ 51, SAN SALVADOR, EL SALVADOR, CENTRAL AMERICA. SEMESTRAL JOURNAL JANUARY-JuNE 2020

\title{
Las TIC como nexo cultural entre salvadoreños migrantes y su país
}

\section{ICT as a cultural link between migrant Salvadorans and their country}

Willian Carballo ${ }^{1}$ Coordinador de investigación, Escuela de Comunicación Mónica Herrera, de El Salvador Maestro en Comunicación por la Universidad Centroamericana, UCA Aspirante a doctor en Sociedad de la Información y el Conocimiento por la Universidad Oberta de Cataluña, España wcarballo@monicaherrera.edu.sv

Fecha de recepción: 30 de septiembre de 2019 Fecha aprobación: 18 de mayo de 2020 DOI: $10.5377 /$ ryr.v51i0.9843 


\section{RESUMEN}

Las tecnologías están cambiando la forma en que los migrantes se relacionan con sus países. La diáspora salvadoreña, que suma 2.1 millones de personas solo en Estados Unidos, las ha utilizado para estar en contacto con sus familiares. Sin embargo, páginas web de radios y canales televisivos, los streaming y las redes sociales han propiciado procesos de hibridación cultural que complejizan la relación con su país de origen y con el que los recibió. A partir de una metodología mixta (cualitativa y cuantitativa) que implicó el uso de una encuesta y entrevistas a profundidad, la investigación presentada busca entender cómo esos procesos de identidad y transnacionalización de los salvadoreños residentes en Estados Unidos se reconfiguran a partir de su consumo de medios digitales. Los resultados sugieren que las TIC permiten a los migrantes ampliar el acceso a productos culturales salvadoreños, sobre todo noticias y música, lo que los ha vuelto actores importantes en los procesos de consumo, apropiación e incluso creación.

Palabras clave: migrante; El Salvador; TIC; identidad nacional; cultura; hibridación.

\section{ABSTRACT}

Technologies are changing the way migrants relate to their countries. The Salvadoran Diaspora, which amounts to 2.1 million just in the United States, has used them as a way of being in touch with their families. However, web pages of radio and television channels, streaming and social networks have led to cultural bybridization processes that make the relationship with their country of origin and with the one they are living in complex. From a mixed methodology (qualitative and quantitative) that involved the use of a survey and in-depth interviews, the research seeks to understand how these processes of identity and transnationalization of Salvadorans residing in the United States are reconfigured from their consumption of digital media. The results suggest that ICTs allow migrants to expand access to Salvadoran cultural products, especially news and music, which has made them important actors in the processes of consumption, appropriation and even creation of these kind of products.

Key words: migrant, E1 Salvador, ICT, national identity, culture, hybridization. 


\section{Introducción}

La diáspora salvadoreña en Estados Unidos la componen cerca de 2.1 millones de personas. Muchas de ellas llegaron al país norteamericano de manera ilegal, otras no. Sin embargo, la gran mayoría huyó de una nación que les ofrecía pocas opciones laborales, anteriormente envuelta en una guerra civil y hoy en día abatida por altos índices de violencia social; por lo que viajaron en busca de empleo y de mejores condiciones de vida (Marroquín, 2013, Rivas, 2016). Esta cifra los convierte en la tercera comunidad hispana con mayor presencia en ese país, después de mexicanos y puertorriqueños. A la vez, tal cantidad es el equivalente a una tercera parte de la población de salvadoreños que habitan dentro de las fronteras del país centroamericano, compatriotas que subsisten en una economía sostenida en buena medida por las remesas provenientes de estos migrantes (Rocha, 2008).

Comolo han recogido estudios recientes (Benítez, 2011; Barrera, 2012; Marroquín, 2013), la gran mayoría de esta diáspora mantiene contacto con sus familiares y amigos que permanecen en El Salvador, gracias principalmente a las Tecnologías de la Información y la Comunicación (TIC) y a las visitas -en el caso de aquellos bajo estatus legal- a sus pueblos o ciudades de origen, donde participan de eventos culturales (Marroquín, 2007), o bien a los actos patrios que suceden en suelo norteamericano.

Por otro lado, las herramientas digitales han permitido a medios de comunicación e industrias como el cine, la televisión y la música ampliar sus audiencias y traspasar fronteras con facilidad, lo que conlleva más facilidad para los salvadoreños residentes en otros países de entrar en contacto con las producciones culturales de su país de origen.

A partir de ese contexto, este artículo muestra los resultados de una investigación cuyo objetivo era entender cómo los procesos de identidad y transnacionalización de los salvadoreños residentes en Estados Unidos se reconfiguran a partir de su consumo de medios digitales de su país y de los productos culturales que estos transmiten.

Algunos trabajos previos sobre la migración salvadoreña ya han explorado esa relación migración-cultura pero desde otras perspectivas o alcances. José Luis Benítez, por ejemplo, indagó en su tesis doctoral la manera en que los medios de habla española en Estados Unidos y programas transnacionales de radio y televisión salvadoreños contribuyen a la formación de identidades híbridas (Benítez, 2005).

Amparo Marroquín, por su parte,exploró cómolas fiestas patronales que se realizan una vez al año en cada pueblo y ciudad de El Salvador representan un espacio de encuentro entre la cultura local y la cultura de los extranjeros y salvadoreños migrantes (Marroquín, 2007). Marroquín y Martel (2007), en cambio, analizaron canciones populares (principalmente corridos y rap) que narran crónicas de migración hacia Estados Unidos, concluyendo que estas contribuyen a la construcción de la identidad migrante, a través de la recolección de lo marginal y la vida cotidiana de sectores social y económicamente marginados. Mientras que Castellón (2013) evaluó los comentarios posteados en YouTube a algunos videos de canciones que tratan sobre la 
identidad salvadoreña o sobre la melancolía por el país. Concluyó que este tipo de videos generan nostalgia en la comunidad migrante, la cual favorece la construcción de identidad nacional.

Rivas (2016) se concentró en la pérdida de identidad de los salvadoreños que migran. Desde su punto de vista, se adoptan costumbres y modos de vida fuera de su patrón cultural originario; se cambian hasta los patrones alimenticios, el gusto musical y hasta se ejerce una fuerte influencia en el grupo de origen o familiares para que adopten las nuevas costumbres del país donde se radica como inmigrante. En un sentido opuesto, Huezo (2009) había antes establecido que la "economía de los vínculos", basada en el consumo nostálgico, no existiría si no fuera porque los migrantes llevan consigo tradiciones, apetencias y modos de convivir que recrean el mundo familiar, un mundo con el cual necesitan tomar contacto y hacer presente en los nuevos espacios que ocupan (p. 91).

Huezo, junto a Marroquín, también trabajaron juntos el capítulo sobre cultura y migración del Informe sobre Desarrollo Humano El Salvador 2005 (PNUD, 2005). Ahí sugerían algunos desafíos para la construcción de un nuevo "nosotros". Entre estos destacaban la necesidad de reconocer que E1 Salvador es un país diverso que no puede ser concebido solo como homogéneo por su lengua o su mestizaje racial indohispano. También advertían que la identidad no debe definirse mediante clichés ("somos trabajadores" o "nos gustan las pupusas"); sino más bien hablar de varias identidades salvadoreñas que no tienen que ser inamovibles. Además, sugieren la constitución de la nueva identidad debe pensarse tomando en cuenta procesos de globalización en los que "lo nuestro" se construye a partir de lo local, lo regional, lo nacional y lo global.

El estudio más cercano al presentado en este artículo es una encuesta especial para el citado informe del PNUD (elaborado por la Universidad Tecnológica), que evaluó las representaciones culturales y percepciones políticas en migrantes salvadoreños, en el Aeropuerto Internacional E1 Salvador, en 2005. Entre los datos más relevantes destacan que ocho de cada diez dijeron que sí se informan por la televisión; y en aquel entonces (2005), solo tres de cada diez lo hacían por internet.

Dicho estudio fue hecho en 2005, cuando las redes sociales y el internet no tenían aún el peso que sí tienen ahora. Algunas investigaciones posteriores sí evaluaron específicamente este punto, aunque no profundizaron en el consumo cultural. Así, Benítez (2008) investigó los mapas culturales y expresiones de identidades colectivas que la diáspora salvadoreña construye día a día en el ciberespacio; utilizando radios en línea y plataformas de redes sociales como MySpace y Facebook. Y en una investigación posterior centrada en la comunicación entre familias con nexos acá y allá, el mismo autor encontró que estas tecnologías son fundamentales en la construcción de una nueva manera de convivir de manera transnacional, que hace posible sostener el sentido de pertenencia y de inclusión en las decisiones trascendentales que importan a los miembros de las familias (Benítez, 2011). Por su parte, Barrera (2012) indagó ese mismo terreno de las TIC y migración hacia Estados Unidos, pero relacionadas a los jóvenes como elementos de comunicación e identidad. Una 
de sus conclusiones fue que estos no consideran un riesgo la adopción de costumbres, valores o conocimientos de la cultura del país norteamericano porque los procesos de alienación no los ven como automáticos, sino dependientes de factores como la educación y la calidad de la comunicación sostenida con su país de origen.

De tal forma que la presente investigación surge de la necesidad de contar con un estudio que brinde datos más actualizados y específicos sobre ese consumo cultural de los migrantes salvadoreños que permitan conocer cómo las dinámicas generadas por la irrupción de las TIC, en años recientes, han influido en estos procesos. Esto es coherente con los planteamientos de Retis (2013), cuando asegura que más recientemente "las investigaciones han dejado de apuntar mayoritariamente a los medios masivos tradicionales para concentrarse en los entornos de consumo de los nuevos medios" (p. 23).

Retis (2012) también establece que el transnacionalismo de la diáspora se advierte menos como "un lugar" y más como "un espacio". Este complejo cambio de paradigma invita "a considerar la posible emergencia de formas contradictorias pero viables de 'comunidades transnacionales imaginadas', especialmente a través de la participación selectiva y parcial en las prácticas comunicativas" (Geourgiou, 2006, en Retis, 2012, p. 6).

Es decir, en palabras de García-Canclini (2003), ocurre una hibridación. Esta se entiende como los procesos socioculturales en los que estructuras o prácticas discretas, que existían en forma separada, se combinan para generar nuevas estructuras, objetos y prácticas. Dichos procesos son incesantes y variados, agrega al autor. Además, llevan a jubilar la idea de identidades "puras", como si solo se tratara de un conjunto de rasgos fijos; y también a no afirmarlas como la esencia de una etnia o una nación. "En un mundo tan fluidamente interconectado, las sedimentaciones identitarias organizadas en conjuntos históricos más o menos estables (etnias, naciones, clases) se reestructuran en medio de conjuntos interétnicos, transclasistas y transnacionales". (p. 6).

Siguiendo esa lógica, la experiencia de migración supone un desplazamiento físico y un proceso de desterritorialización o desanclaje cultural que se reterritorializa en un nuevo sistema social (Giddens, 1991, en Benítez, 2008, p. 48). Es justamente en esa lógica de hibridación, como propone Karim (2003, en Benítez, 2008, p. 48), que se vuelve importante analizar cómo los diferentes medios de comunicación colectiva (programas de televisión y radio, música popular, periódicos, revistas, videos caseros, teléfonos celulares, sitios web, entre otros) crean y mantienen recursos simbólicos para la producción y negociación de identidades colectivas en el espacio social transnacional.

\section{Metodología}

Para el estudio se utilizaron técnicas mixtas. Por un lado, se ocupó un método cuantitativo, mediante la herramienta de encuesta de carácter descriptiva. La muestra incluyó a salvadoreños que radicaran en los Estados Unidos, mayores de 18 años, a través de un muestreo no 
probabilístico utilizando la técnica de sujeto referenciado y bola de nieve, realizada entre el 3 de noviembre de 2018 al 13 de enero de 2019. El estatus legal de los encuestados no fue considerado como determinante en la selección de la muestra.

El tamaño de la muestra fue de 309 encuestas efectivas con un margen de error del 5.6\% y un nivel de confianza del 95\%. Los encuestados pertenecían a los estados estadounidenses con mayor cantidad de población: California (37 por ciento); aquellos cercanos al área metropolitana de Washington D. C. (14. 3 por ciento); Texas (13.6 por ciento) y Nueva York (11 por ciento). El resto se distribuyó en varios estados donde también habitan salvadoreños, pero en menor proporción. Además, el 33. 7 por ciento tenía hasta 5 años de residir en Estados Unidos; 34.3 por ciento entre 6 y 15 años; 19.7 por ciento entre 16 a 25 años y 12.3, más de 25 años. Por otro lado, 57.6 por ciento fueron mujeres y 42.4 hombres.

Los resultados cuantitativos se complementaron con 10 entrevistas cualitativas a profundidad. Acá se buscaba conocer detalles sobre las formas de consumir, de apropiarse y usar los productos culturales, que permitieron explorar el cómo y el porqué, más que las meras frecuencias o negaciones y afirmaciones de la herramienta cuantitativa. De igual forma, se buscó que entre los entrevistados hubiera más representantes de los estados con más salvadoreños; aunque también se incluyeron a algunos procedentes de estados donde la comunidad originaria del país centroamericano es pequeña.

\section{Resultados de la investigación}

En este apartado se presenta, primero, una aproximación al sentido de identidad con su patria manifestado expresamente por los migrantes salvadoreños radicados en Estados Unidos. Luego, se expone el consumo de medios digitales y de diferentes productos culturales transmitidos a través de ellos.

\section{Identidad y nostalgia}

A los encuestados, previamente, se les preguntó ¿qué tanta nostalgia sienten por su país? Entre los que dijeron que "mucha"y "muchísima" suman 65 por ciento. Destaca un 2.3 que contestó que "ninguna". Una joven de 23 años que en entrevista cualitativa mencionó que no extraña “tantas cosas" de su país, manifestó que no siente nostalgia porque las personas más importantes de su vida están, al igual que ella, en Estados Unidos -salvo excepciones como una tía y una sobrina-. Ella estudia, tiene trabajo y pareja.

En ese sentido, destaca que un 20 por ciento no regresaría a El Salvador a vivir definitivamente si se le presentara la oportunidad y 18 por ciento "se lo pensaría". Incluso la respuesta más repetida (37.2 por ciento) establece una condición para volver: "Regresaría si las condiciones del país fueran buenas". Las entrevistas a profundidad permitieron conocer que, específicamente, se refieren a que el país debería antes resolver problemas de violencia y falta de oportunidades, así como ofrecer buenos empleos o posibilidades de desarrollarse económicamente. 


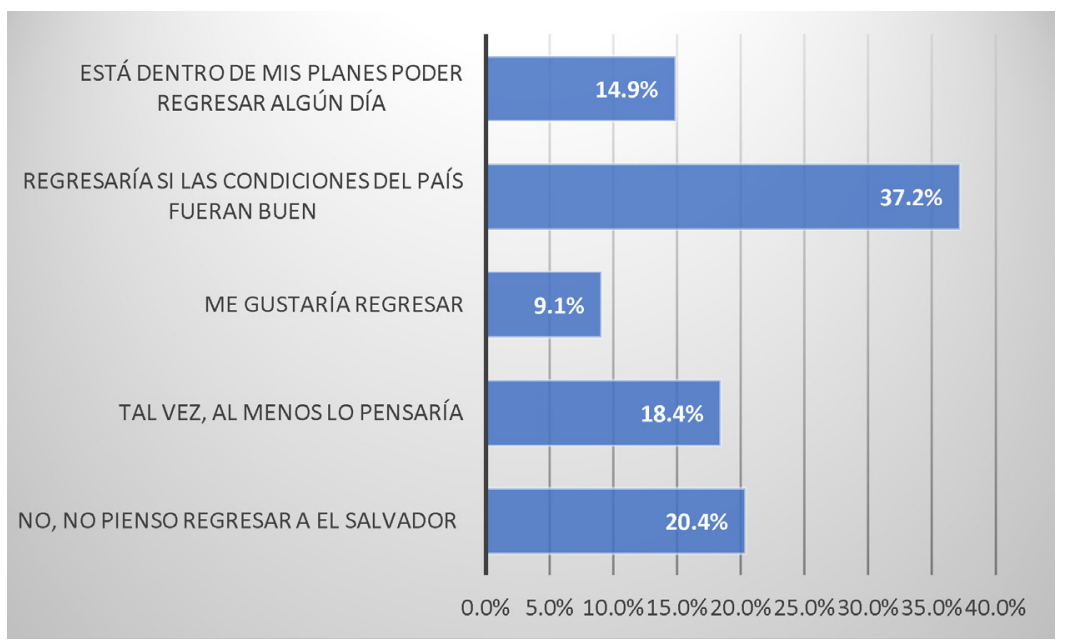

Gráfico n. ${ }^{\circ}$. Si un día tuviese la posibilidad de regresar a El Salvador, ¿¿volvería a vivir? Fuente: elaboración propia.

Aquellos que tienen hijos, ¿les fomentan la cultura de su país de origen? Dos terceras partes de los encuestados que cumplen con esa condición manifestaron que "se preocupan" y "se interesan" en que no pierdan sus raíces salvadoreñas, hablándoles con frecuencia sobre su patria. Solo un cuatro por ciento respondió que "nunca" lo hace, como se observa en el gráfico 2.

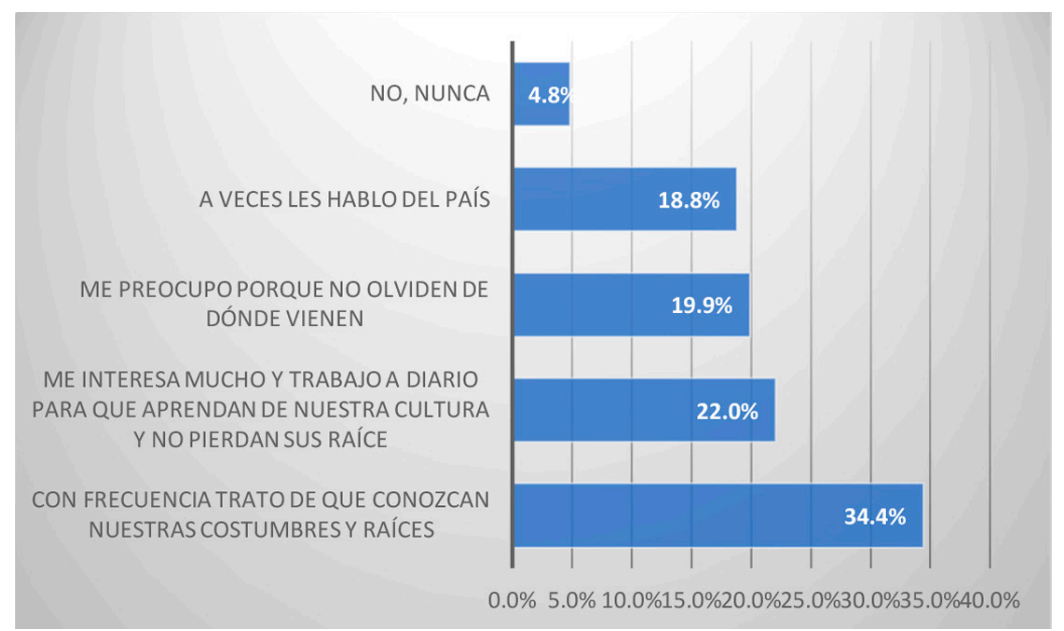

Gráfico $n .^{\circ} 2$. Si tiene hijos viviendo en el hogar, ¿les fomenta la cultura salvadoreña? Fuente: elaboración propia 
Una de las formas de fomentar la identidad patriótica, comentaron algunos entrevistados a profundidad, es hablándole de los personajes salvadoreños más importantes. La encuesta reveló que esos personaje son, principalmente, Monseñor Óscar Arnulfo Romero (con 54 por ciento de respuestas) y Jorge el Mágico González (muy atrás, con 18.1 por ciento). Romero se convirtió en 2018 en el primer santo salvadoreño de la Iglesia Católica, hecho que "alegra" y "tiene mucho significado" para casi la mitad de la muestra; y González es el futbolista de este país que más ha destacado a nivel mundial, aunque esto ocurrió tres décadas atrás. Ambos son, en efecto, los íconos culturales salvadoreños más reconocibles en el extranjero (Carballo, 2018)

Otro de los aspectos evaluados es la frecuencia con la que visitan El Salvador. La respuesta más repetida fue una vez al año, con 26 por ciento; mientras que el 15 por ciento mencionó nunca haber venido, aún y cuando tengan "papeles" (es decir, un estatus legal en regla). Entrevistas cualitativas permitieron conocer que entre quienes permanecen indocumentados, y por lo tanto les es contraproducente salir del Estados Unidos, persiste un alto deseo de hacerlo, en especial aquellos cuya familia cercana permanece en su país de origen.

Pero qué pasa cuando no son ellos los que vienen a E1 Salvador si no que El Salvador va hacia donde ellos. En ocasiones, los consulados y empresas privadas realizan actividades culturales en suelo estadounidense, en especial para la independencia patria (septiembre) o para las fiestas patronales en honor al Divino Salvador del Mundo, patrono de San
Salvador, capital del país (agosto). También suelen haber conciertos, convivios y otro tipo de encuentros; a los que asisten artistas de rock o de cumbia salvadoreña, a los cuales presentadores de la televisión nacional viajan desde Centroamérica, exclusivamente para ser maestros de ceremonias. Sin embargo, solo 28 por ciento de la muestra dijo asistir a este tipo de encuentros, y regularmente lo hacen una vez al año. Cuando se les pregunta a cuál han ido, la celebración con más menciones es la fiesta de la Independencia (58 por ciento), seguida de eventos culturales, como conciertos, desfiles, exposiciones, etc. (48 por ciento).

Los eventos deportivos también son otro punto de encuentro salvadoreño en tierra estadounidense. Sin embargo, dado que los partidos principalmente de la Selección de Fútbol de E1 Salvador- no suelen ser muy continuos (unas tres o cuatro veces al año) y pueden ser en cualquiera de los estados del país norteamericano, solo un 22 por ciento manifestó haber asistido a algún partido. Sin embargo, un porcentaje mayor (33 por ciento) sí dice estar pendiente de los juegos de la Selección, principalmente a través de redes sociales, transmisiones en línea o cuando el partido es emitido por televisión.

\section{El papel de los medios digitales}

La gran mayoría de miembros de la diáspora salvadoreña en Estados Unidos que contestaron la encuesta tiene acceso a redes sociales e internet (94 por ciento). Entre ellos, Facebook es la reina, pues nueve de cada diez dice usarla. Le siguen Instagram, YouTube y mucho más atrás otras plataformas como Twitter y WhatsApp, como se aprecia en este gráfico: 


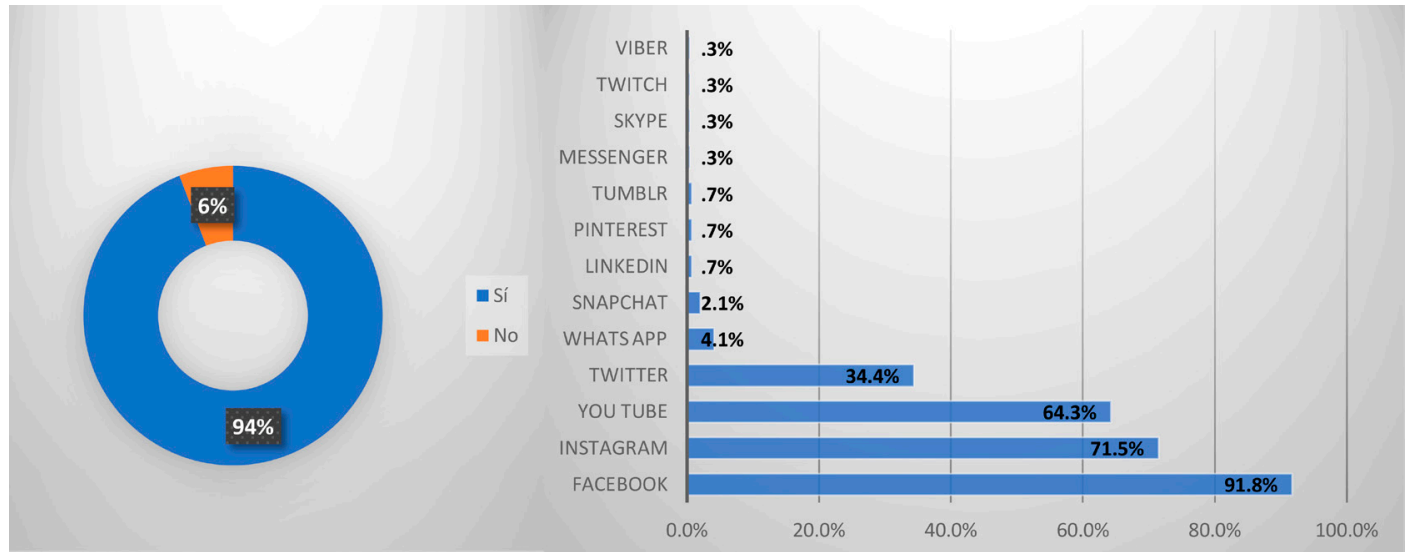

Gráfico n. ${ }^{\circ} 3$. ¿Utiliza redes sociales con frecuencia? ¿Cuáles? Fuente: elaboración propia.

87 por ciento de los entrevistados indicaron que siguen cuentas relacionadas con El Salvador. Mientras que 77 por ciento manifestó que se mantiene pendiente de lo que ocurre en su país, aunque el mayor porcentaje dijo estar "algo informado" (44 por ciento), contra apenas el nueve por ciento que se considera "muy informado".

El tipo de cuentas que más siguen son aquellas vinculadas con medios de comunicación y de partidos o figuras políticas, como se ve en el gráfico 4. En relación con esto último, es importante matizar que la respuesta pudo estar condicionada con que la encuesta se realizó en época electoral (semanas antes de las elecciones presidenciales de 2019). Muy pocas personas dijeron seguir páginas de memes o de humor, o bien aquellas nostálgicas (que publican fotos de antaño, por ejemplo).

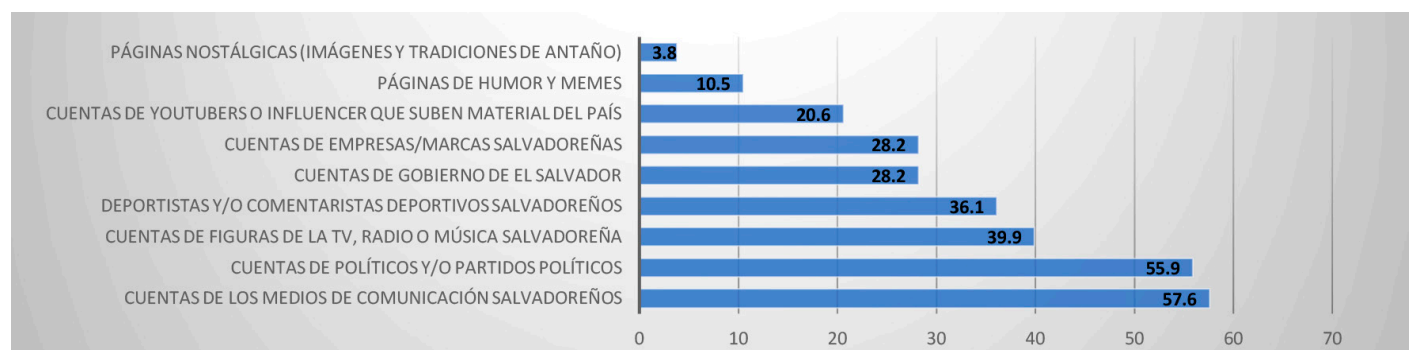

Gráfico n. ${ }^{\circ}$. ¿Qué tipo de cuentas sigue en redes sociales? Fuente: elaboración propia. 
Para acceder concretamente a noticias sobre El Salvador lo hacen a través de periódicos salvadoreños en línea. Los dos primeros que mencionaron fueron dos medios autóctonos del papel que han dado el salto a la web (La Prensa Gráfica y El Diario de Hoy); el tercero, sin embargo, es El Faro, periódico nacido en el ciberespacio a finales del siglo pasado. Los leen o bien tres veces a la semana o bien todos los días.

Otras formas que los encuestados radicados en Estados Unidos tienen para acceder a noticias sobre su país de origen es lo que les cuentan sus familiares que habitan dentro del territorio salvadoreño. En entrevistas cualitativas trascendió que cuando se comunican por redes sociales o por teléfono aprovechan para informarse del acontecer nacional. También hay un 39 por ciento que lo hace a través de noticieros en línea; y un 36 por ciento que se informa vía medios noticiosos estadounidenses.

Acá es importante matizar que algunos migrantes que manifiestan haber visto algún reporte sobre El Salvador en estas televisoras estadounidenses (sea en inglés o español dirigidas a públicos hispanos), perciben un país "con bastantes problemas", de tal forma que "se asustan" por lo que está sucediendo. Pero cuando le preguntan a sus familiares por la supuesta gravedad de tal suceso, se enteran de que no tenía la magnitud que originalmente habían percibido. Por ejemplo, una nota sobre un temblor fuerte suele alarmar mucho a los salvadoreños migrantes; pero luego, al contrastar con lo que dicen sus familiares, resulta que no era un movimiento telúrico tan alarmante como la noticia se los hizo ver; o bien, que no fue sensible en todo el territorio nacional, sino en algunos departamentos. Lo mismo pasa con algunas notas sobre violencia o sobre condiciones climáticas adversas.

Por otro lado, las noticias que más les gusta leer (de nuevo, las elecciones pudieron influir) son las políticas, seguidas de las de economía, violencia y migración, como se observa en el siguiente gráfico:

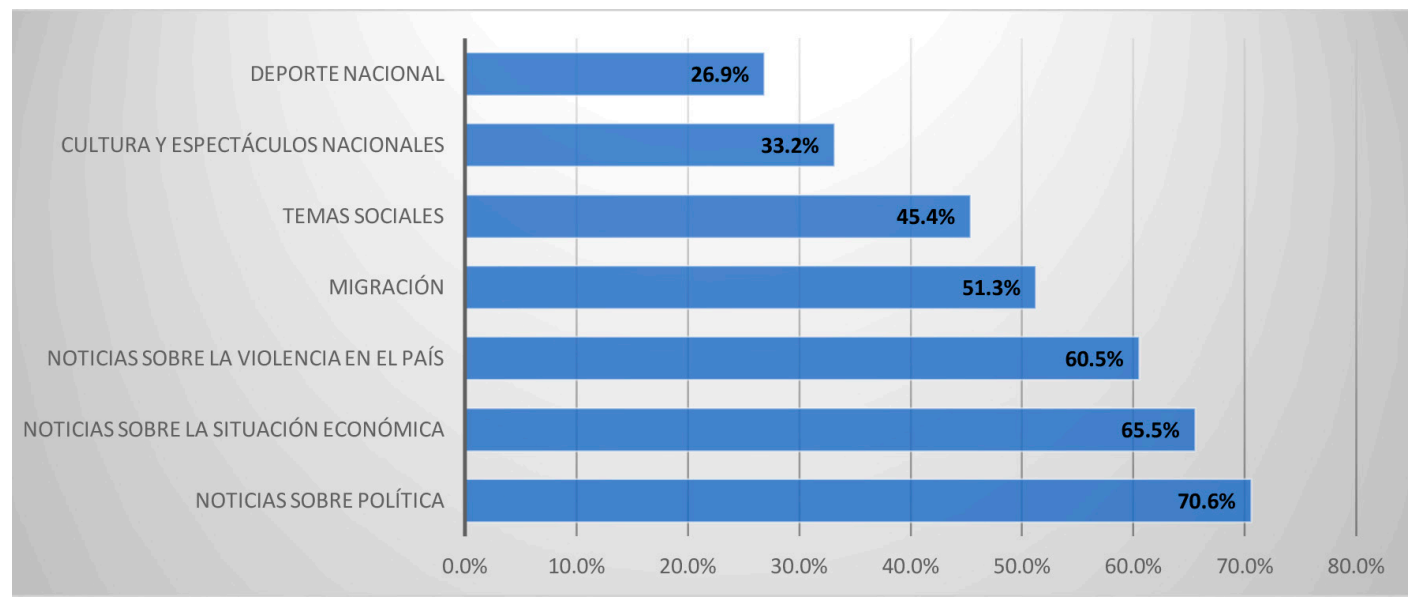

Gráfico n. ${ }^{\circ}$ 5. ¿Qué noticias le interesa más leer? Fuente: elaboración propia. 
Más allá de las noticias, el salvadoreño en los diferentes estados del país del norte también consume vía internet otros productos culturales, aunque en menor medida. Por ejemplo, del 100 por ciento de entrevistados, solo 28 dijo escuchar radios salvadoreñas en línea. Cuando lo hacen, prefieren oír música variada o bien, de nuevo, programas sobre política (entrevistas o debates).

En cambio, cuando se trata de música salvadoreña, seis de cada diez sí la escucha, aunque la mayoría lo hace de forma "muy eventual". El medio predilecto para tal acción es la plataforma YouTube (83 por ciento). Otras formas de acceder a estas producciones son los servicios de descarga o bien vía las radios salvadoreñas. La gran mayoría escucha cumbias, un género que estuvo muy de moda en los noventa en el país, cuando a lo mejor muchos de ellos aún vivían en El Salvador y, por lo tanto, les trae recuerdos. En YouTube se encuentra una gran variedad de videos musicales de artistas salvadoreños. Y como lo contó Castellón (2013), estos son una importante vía para establecer vínculos identitarios con el país que dejaron atrás.

Otras manifestaciones culturales, en cambio, no gozan de tanta popularidad. Por ejemplo, solo uno de cada diez ve cine salvadoreño. Sin embargo, es importante recordar que la producción cinematográfica del país es escasa, muy a pesar de que haya habido un repunte en los últimos años. Cuando han visto alguna producción fílmica, lo hacen a través de YouTube, donde, en efecto, algunos usuarios han subido algunas locales, sobre todo documentales. Leer libros salvadoreños tampoco es una práctica muy establecida, pues solo dos de cada diez dijeron hacerlo, habiendo leído un promedio de 2.2 libros por año, principalmente a Salarrué y Roque Dalton, dos de los principales autores locales.

\section{Discusión de resultados}

La investigación deja claro que las Tecnologías de la Información y la Comunicación (TIC) sí han reconfigurado los procesos de identidad nacional de los migrantes salvadoreños radicados en Estados Unidos. Los resultados, en coherencia con lo que adelantaba Cohen (2008), confirman que la desterritorialización de las identidades son fenómenos vigentes entre estos grupos poblacionales, pero que las ideas de hogar y de patria sigue siendo, aun así, discursos poderosos para ellos. De manera puntual, se puede afirmar que las amplias posibilidades que generan los medios digitales son, en buena medida, responsables de potenciar dicho proceso, pues facilitan a los migrantes el acercamiento al país que dejaron; un lugar que antes parecía mucho más distante, pero que, al mismo tiempo, luce ahora distinto a sus recuerdos y al contexto social en el cual se desenvuelven en la actualidad.

Ese acercamiento se da a través de dos vías. En primer lugar, los medios digitales les permiten acceder de manera más directa a la información de su país. Ya sea a través de redes sociales, de la comunicación directa vía celular con sus familiares o bien mediante la lectura, vista o audios de periódicos, radios y televisoras salvadoreñas en línea, los migrantes salvadoreños en Estados Unidos ahora acceden a muchas más noticias sobre su patria. La gran mayoría está muy conectada, por lo que sus muros de Facebook (la red social que más siguen) y su relación directa 
con medios específicos escritos o audiovisuales en línea les permiten acceder a noticias de forma más rápida. Luego, sus familiares que permanecen en El Salvador, siempre a través de los celulares o de las mismas redes sociales, se convierten en agentes de confirmación o aclaración de la información recibida.

Este resultado es importante pues implica la necesidad de trabajar a futuro, procesos de alfabetización mediática tanto con los migrantes como con sus familiares, esto con el fin de evitar alarmas innecesarias y de generar un escudo ante noticias falsas, exageraciones o malas interpretaciones, como muchas veces ocurre, según se confirmó en esta investigación. Antes, sin embargo, será necesario profundizar aún más en esos procesos de apropiación y uso de las noticias.

En segundo lugar, las nuevas tecnologías también han posibilitado a la diáspora tener más acceso a productos culturales que le recuerden a su "patria querida", como dice una de las principales canciones salvadoreñas dedicadas a los migrantes. Hasta hace unos quince años, escuchar las canciones de los artistas que oían cuando los hoy migrantes vivían en El Salvador -los que nacieron acá- dependía del comercio de discos (oficiales o piratas) o de las giras que estas agrupaciones musicales o solistas realizaran por California, Texas, Washington o cualquier otro estado donde hubiera una comunidad numerosa. Además, volver a ver sus programas de televisión favoritos estaba supeditado solo a la posibilidad de visitar su país o bien mirar un viejo videocasete. Hoy, en cambio, buena parte de las canciones, películas, libros, comerciales de televisión de antaño, programas de televisión y otras producciones culturales que le recuerden y conecten con su país están en YouTube, a tan solo un clic de distancia.

Esto también tiene implicaciones, pues vuelve los espacios transnacionales más complejos. Ahora, en su consumo cultural cohabitan la cultura estadounidense -que es obviamente fuerte $y$ también tiene más canales de difusión gracias a internet- con esta otra creciente oferta nostálgica sobre su patria que ofrecen los nuevos medios. Esa conjunción sigue causando procesos importantes de hibridación, con consecuencias diferentes para adultos migrantes que para los hijos de estos. De ahí que un reto para futuras investigaciones sea profundizar en el consumo particular de los más jóvenes (el estudio acá presentado solo incluyó mayores de 18 años y el de Barrera data de 2012 cuando el acceso era menor), para saber cómo las nuevas generaciones se relacionan con los productos que escuchaban sus padres y que cada vez se volverán más viejos. Es de suponer que, para ellos, estos productos culturales ya no tendrán el mismo efecto de generar identidad patriótica como sí lo causa en sus padres. Importante será, entonces, saber qué les significa.

\section{Bibliografía}

Barrera,J. (2012). Comunicación e identidad de jóvenes salvadoreños hijos de padres migrantes. Tesis para optar al grado de Maestro. Antiguo Cuscatlán: Universidad Centroamericana José Simeón Cañas (UCA).

Benítez, J. L. (2005). Communication and collectitive identities in the transnational social space: a media ethnography of the salvadoran immigrant community in the Washington D.C Metropolitan Area. Dissertation for Doctor of Philosophy. Ohio: Ohio University. 
Benítez, J. L. (2008). Diáspora salvadoreña: identidades y mapas culturales en el ciberspacio. Encuentro, 46-56.

Benítez, J. L. (2011). La comunicación transnacional de las familias e-migrantes. San Salvador: PNUD/UCA.

Carballo, W. (2016). Centroamérica, una pelicula de Hollywood. Representación de los paises del área y sus migrantes en series y filmes de ficción estadounidenses de 1900 a 2015. Santa Tecla: Mónica Herrera Ediciones.

Carballo, W. (2018). El mago y el beato. Ensayo sobre dos iconos culturales de un pais de pocos iconos. San Salvador: Ministerio de Cultura de E1 Salvador.

Castellón, R. M. (2013). Análisis de los relatos de nación que se construyen a partir de los comentarios en YouTube sobre los videos musicales que identifican a los salvadoreños migrantes. Tesis para el grado de Maestría. Antiguo Cuscatlán, El Salvador: Universidad Centroamericana José Simeón Cañas UCA.

Cohen, R. (2008). Global diasporas. An introduction. Londres: Routledge.

García Canclini, N. (1999). El consumo cultural: una propuesta teórica. En G. Sunkel, El consumo cultural en América Latina (págs. 26-49). Bogotá: Convenio Andrés Bello.

García Canclini, N. (2003). Noticias recientes sobre la hibridación (Revista Transcultural de Música).
Hall, S. (1997). El trabajo de representación. En S. Hall, Representation: Cultural Representations and Signifying Practices. (págs. 13-74). Londres: Sage Publications.

Huezo, M. (2009). Un pie aquí y otro allá. Los migrantes y la crisis de la identidad salvadoreña. San Salvador: Centro Cultural de España de El Salvador.

Lozano, E. (1999). Del sujeto cautivo a los consumidores nomádicos. En G. Sunkel, El consumo cultural en América Latina (págs. 50-64). Bogotá: Convenio Andrés Bello.

Marroquín, A. (2007). El Salvador del Mundo. Migración, cultura y fiestas patronales de los salvadoreños. San Salvador: UCA-SKM.

Marroquín, A. (2013). La migración centroamericana.Apuntes para un mapa provisional. Estudios Centroamericano ECA, 91-103.

Marroquín, A., \& Martel, R. (2007). Crónica de fronteras: la música popular y la construcción de la identidad salvadoreña migrante. Istmo.

Martín-Barbero, J. (1999). Recepción de medios y consumo cultural: travesías. En G. Sunkel, El consumo cultural en América Latina (págs. 2-25). Bogotá: Convenio Andrés Bello.

PNUD. (2005). Informe sobre desarrollo humano El Salvador 2005. San Salvador: PNUD.

Retis, J. (2012). Inmigrantes territoriales / Inmgirantes digitales. Latinoamericanos en contextos diaspóricos. 140 Encuentro Latinoamericano de Facultades de Comunicación Social. Lima: FELAFACS. 
Retis, J. (2013). Estudio exploratorio sobre el consumo cultural de los inmigrantes latinoamericanos en España el contexto transnacional de las prácticas culturales. Fundación Alternativas.

Rivas, R. (2016). Migraciones, causas y nuevas identidades. Revista de Museología, Págs. 101-116.

Rocha,J.L. (2008). Centroamérica. El fetichismo de las remesas. Razón y fe, 277-292.

\section{Notas al final}

1 Con asesoría cuantitativa de Jorge Castillo y apoyo en las entrevistas cualitativas de Jaqueline Herrera y Francela Amaya. 